\title{
An Appraisal of Spatial Distribution of Solid Waste Disposal Sites in Kano Metropolis, Nigeria
}

\author{
Ali Ibrahim Naibbi, Umar Musa Umar \\ Geography Department, Northwest University, Kano, Nigeria \\ Email: Sarkinaibbi@gmail.com, umarsurely@gmail.com
}

How to cite this paper: Naibbi, A.I. and Umar, U.M. (2017) An Appraisal of Spatial Distribution of Solid Waste Disposal Sites in Kano Metropolis, Nigeria. Journal of Geoscience and Environment Protection, 5, 24-36

https://doi.org/10.4236/gep.2017.511003

Received: September 16, 2017

Accepted: November 5, 2017

Published: November 8, 2017

Copyright $\odot 2017$ by authors and Scientific Research Publishing Inc. This work is licensed under the Creative Commons Attribution International License (CC BY 4.0).

http://creativecommons.org/licenses/by/4.0/

\begin{abstract}
This paper describes a research project that has been conducted as part of the Kano Municipal waste management strategy. The aim is to quantify and to identify the existing locations of waste disposal sites by mapping their spatial distribution within the metropolitan Kano. QUICKBIRD satellite imageries; locations of existing waste disposal sites collected using Global Positioning System (GPS); and topographical map (1:5000 scale) of Kano metropolis were used to generate data for the study. The data were prepared and analysed using ArcMap 10.2.1 and Erdas Imagine 11 software to produce the spatial distribution maps for solid waste disposal sites within the metropolis. The result shows that out of the 300 existing waste disposal sites assessed, the city has fairly well-distributed waste disposal sites. Conversely, the disposal sites are more clustered in the centre of the metropolis than the outskirts. However, about 80 percent of the sites are either located very close to roads, settlements or water bodies. Also, while about 92 percent of the existing waste disposal locations are open space, only about 7 percent are containers (closed dumping sites). Correspondingly, about 89 percent are authorised dumping sites and only about 11 percent are unauthorised illegal. The study recommends that policymakers should intervene and relocate the existing unauthorized dump sites to more suitable areas.
\end{abstract}

\section{Keywords}

Solid Waste, Waste Disposal Sites, Waste Management, REMASAB

\section{Introduction}

Waste is a material discharged and discarded from each stage of daily human life 
activities, which leads to adverse impacts on human health and the environment [1]. Solid wastes are discarded materials such as; leaves/twinges, food remnants, paper/cartons, textile materials, bones, ash, dust, stones, dead animals, human and animal excreta, construction and demolishing debris, biomedical debris and household hardware [2] [3] [4]. Among all the wastes (solid, liquid and gas), solid waste is the most popular and most difficult to manage locally. This is because solid waste does not flow, evaporate, diffuse, dissolve or absorbed into the surrounding, unlike liquid and gaseous wastes [5]. This is why Singh et al. [6] suggested that the management of solid waste should include waste generation, on-site handling, storage and processing, collection, transport, sorting and recycling, treatment and reuse as well as disposal options.

Therefore, it can be argued that solid waste disposal is an integral part of waste management system, which requires much attention in order to avoid environmental pollution and health problems. However, most solid waste disposal sites are found on the outskirts of the urban areas where there are water bodies, crop fields, settlement, roads, etc. These sites are normally favourable locations for the incubation and proliferation of vermin, which transfer diseases that affect human health [7]. Inappropriate disposal of solid waste can result in contamination of surface and groundwater through leaching, soil contamination through direct waste contact, air pollution by burning of wastes, spreading of diseases by different vectors like birds, insects and rodents, or uncontrolled release of methane by anaerobic decomposition of waste [8]. Solid wastes indiscriminately disposed of results in aesthetic problems, nuisances, and pollution of land and water bodies of an area [9] [10]. Rahman [10] noted that the most common problems associated with improper disposal and management of solid waste include disease transmission (such as cholera, malaria, dengue, conjunctivitis, skin irritations etc.), fire hazards, odour nuisance, atmospheric pollution, aesthetic nuisance and economic losses. United Nations Environment Programme (UNEP) [11] noted that poor waste management-ranging from non-existing collection systems to ineffective disposal causes air pollution, water and soil contamination.

Similarly, the increasing volume and complexity of waste associated with modern economy pose a serious risk to ecosystems and human health. Every year, an estimated 11.2 billion tons of solid waste are collected worldwide [11]. UNEP [11] noted that in most developing countries, open dumping with open burning is the norm in terms of waste management. This is an indication that there is lack of commitment by the majority of the developing countries in their waste management activities. For example, Hansen [12] highlighted that before the 2008 Morocco reform on waste management, more than 5 million tons of solid waste is generated in Morocco and only 70 percent use to be collected; while only less than 10 percent of the collected waste is being disposed of in an environmentally and socially acceptable manner. Nigeria that has a population of over 170 million and rated as one of the largest producers of solid waste in Africa, generates about 35 million tons of solid waste annually [13], out of which 
only between 10 and 30 percent is collected [13] [14] [15]. Most of the wastes are generated by households, and in some cases, by local industries, artisans and traders, which littered the immediate surroundings. The management of these wastes is among the most pressing environmental challenges facing urban authorities in Nigeria. For example, Bakare [13] highlighted that Lagos state with a per capita waste generation of $0.5 \mathrm{~kg}$ per day generates more than 10,000 tons of urban waste every day experienced delays in the collection of its household solid waste. In some cases, the wastes are not collected until after a week or two. Consequently, the waste bin overflows and litters the surroundings. Another negative practice is the overloading of collection trucks with up to 5 to 6 tons of waste in order to reduce the number of trips. This has necessitated the various calls to the government by environmental activists to review the relevant legislature to conform to the modern waste transportation standard. The situation in Ogbomosho and Iseyin of Oyo state is more alarming. These places resorted to waste burning, or dumping the waste along river channels, thus, compounding its waste disposal and management predicament [13]. Kano state has a similar trend with Lagos. However, it should be noted that the state is implementing the mandatory end of the month general sanitation exercise (every last Saturday of the month), where all socio-economic activities start after $10 \mathrm{am}$. Despite this development, it was estimated that about 3100 tons of waste is generated daily in metropolitan Kano and only about 36 percent is evacuated [16]. Nabegu [16] observed that the agency responsible for the collection and disposal of the generated waste in Kano (Refuse Management and Sanitation Board (REMASAB)), is faced with so many problems ranging from constraints of finance, working materials and increasing population of the city. Given these complexities surrounding waste management, researchers and policymakers have since begun to appreciate the role of Geographical Information System (GIS) and Remote Sensing in understanding and addressing part of the problems.

This present study uses GIS and remote sensing and evaluates Kano metropolis' existing solid waste disposal sites. Thus, the objective of the study is to map the spatial distribution of the existing solid waste disposal sites in Kano metropolis. The paper is structured in the following order: Sections 2 and 3 present some information about waste disposal sites, and materials and methods used for the study respectively. Section 4 presents and discusses the results, which highlights the locations, spatial distribution and assessment of the existing solid waste disposal sites in Kano metropolis. The conclusion and recommendations are presented in Section 5, which calls for the relocation of the existing unauthorized waste disposal sites within the metropolis.

\section{Background Information of Waste Disposal Sites}

Although the legal definition of municipal solid waste (MSW) varies from country to country, Kawai and Tasaki [17] conceptualized MSW as the waste managed by or for municipalities as a public service. In other words, solid waste management refers to the supervised handling of waste material from generation 
at source through the recovery processes to disposal. Since 1960, the authorities in Kano have had 13 different agencies tasked with the management of municipal waste as shown in Table 1. Presently, REMASAB is mandated with such task.

\subsection{Authorized versus Unauthorized Waste Disposal Sites}

Certainly, the generation and disposal of waste is an intrinsic part of any country. In Nigeria, solid waste generated from domestic and commercial sources has grown significantly over the last few decades, which is connected with the increasing number of its population, particularly in the cities. The waste disposal practices include among others: self-disposal, discharge, illegal dumping, recycling, collection and final disposal [18]. The wastes, which are a major problem to the environment, are mainly disposed of in open dump sites (either authorized or unauthorized disposal sites). The open dump sites waste is usually burnt and disposed of in the open air, and sometimes scavengers are seen around the dump sites collecting paper, plastic and tin [19].

Basically, an authorized collection site is an approved disposal point by the MSW agency. In many countries, the authorized collection sites may be either open-space or a closed container depending on the situation and alarming environmental factor associated with the location. For example, a disposal point that is too tight with a market and no other place deem suitable around it would necessitate the need for a container so that the waste would not be exposed to the public and nearby settlements. A container is a material made of metallic substances used for storage of refuse (refer to Section 4.2-Figure 6 for the situation in Kano municipal). Marmara University Environmental Biotechnology Group

Table 1. Solid waste management agencies of Kano municipal since independence (1960).

\begin{tabular}{ccc}
\hline S/N & Agency & Period \\
\hline 1 & Kano Native authority & $1960-1969$ \\
2 & Kano Local Government Authority & $1969-1971$ \\
3 & Kano Metropolitan Planning Authority & $1971-1973$ \\
4 & Kano Ministry of Health & $1973-1976$ \\
5 & Kano municipal Local Government & $1976-1982$ \\
6 & Kano state Ministry of Housing & $1982-1983$ \\
7 & Ministry of Local Government and Community Development & $1983-1985$ \\
8 & Metropolitan Environmental Sanitation Task Force & $1986-1990$ \\
9 & Kano state Environmental Planning and Protection Agency (KASEPPA) & $1990-1994$ \\
10 & Refuse Disposal Agency (REDA) & $1994-1998$ \\
11 & Waste Disposal Company (WASCO) & $1998-1999$ \\
12 & Kano ministry of Environment & $1999-2003$ \\
13 & Refuse Management and Sanitation Board (REMASAB) & $2003-$ To Date \\
\hline
\end{tabular}

Source: Adapted from Karry (2008) in Malumfashi et al. [18]. 
(MEBiG) [20] categorized MSW container system collection into; Hauled Container System (HCS) and Stationary Container System (SCS). MEBiG noted that, while HCS is suitable for the removal of wastes from sources where the rate of generation is high, SCS is more suitable for manual loading from residential areas or wheeled from the residential pickup and commercial pickup.

On the other hand, illegal or unauthorized dumping implies that the waste generated is dumped in the vicinity of the source or in a place where such practice is prohibited, such as road site, open space, drainage and valleys. Gilgit-Baltistan-Environmental protection Agency (GB-EPA) ([21]) noted that an unauthorized waste activity represents both waste related activities that are conducted without any due authorization or in significant breach of their authorization. For example, Hussain et al. ([19]) observed that waste is disposed of in unauthorized waste dump sites in seven urban centres of Gilgit-Baltistan (GB) in Pakistan, despite having officially designated dump sites. This clearly demonstrates either the inability of authorities to curtail the problems adequately or the deliberate negative attitude of the people in not complying with the waste management agencies. The authors of this present study agree with both the two assertions because a common problem for MSW management in most Nigerian cities includes institutional deficiencies, inadequate legislation, resource constraints and improper disposal of trash by the residents, which is a form of illegal dumping.

\subsection{Waste Collection Strategy in Nigeria}

The practice of disposing of solid waste indiscriminately is costly in terms of collection, transportation, disposal and recycling. Figure 1 illustrates the common practice of solid waste disposal in Kano municipal. From the figure, the major source of solid waste in Kano is categorized into households, commercial, industrial, institutions and street refuse. Waste collection and transportation implies to the system of waste collection from source to disposal sites. Typically, wheelbarrows are used for collecting and transporting solid waste to dump sites from households and marketplaces, and neighborhoods where trucks cannot access. The wheelbarrows usually discharge at a point (intermediate points) where trucks (about 7 tons capacity) collect it for eventual transportation to the final disposal sites/landfills.

Kano's waste can be categorized into street refuse, urban livestock manure, and industrial or semi-industrial wastewaters [18]. Malumfashi et al. [18] noted that the sources of street refuse in Kano are households, markets, drainage clearance, and street sweeping, which are mostly found at the side of the street

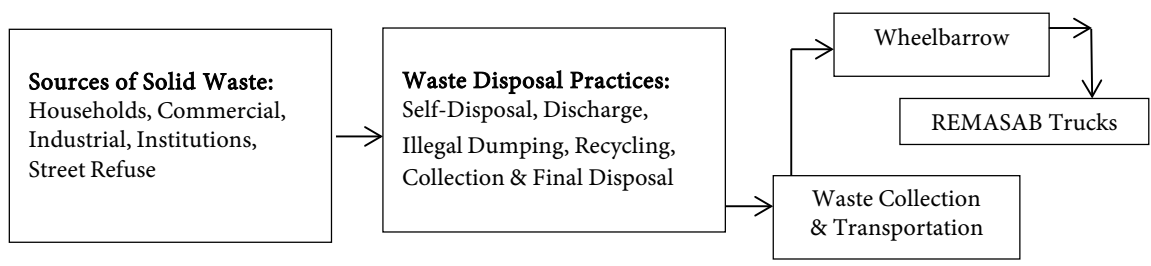

Figure 1. Schema of solid waste disposal practices in Nigeria. 
and on both authorized and unauthorized dump sites. For example, the free roaming of livestock particularly in the ancient city of Kano directly contributes to the huge pile of street refuse in the city. Malumfashi et al. [18] further disclosed that industries in the metropolis are the sources of liquid and gaseous waste. Many studies have highlighted the significance of offal discharge (domestic and industrial wastes) into the drainage systems and streams around the metropolis to the source of surface water pollution within the metropolitan Kano (see, for example, [22]).

\section{Study Area, Materials and Methods}

\subsection{Study Area}

Kano is the administrative centre of Kano state and the third largest city in Nigeria after Lagos and Ibadan. Kano metropolis is located between latitudes $11^{\circ} 52^{\prime} \mathrm{N}$ and $12^{\circ} 07^{\prime} \mathrm{N}$ and longitudes $8^{\circ} 24^{\prime} \mathrm{E}$ and $8^{\circ} 38^{\prime} \mathrm{E}$. It is relatively at the centre of Kano state (see Figure 2). Kano state has a population of approximately

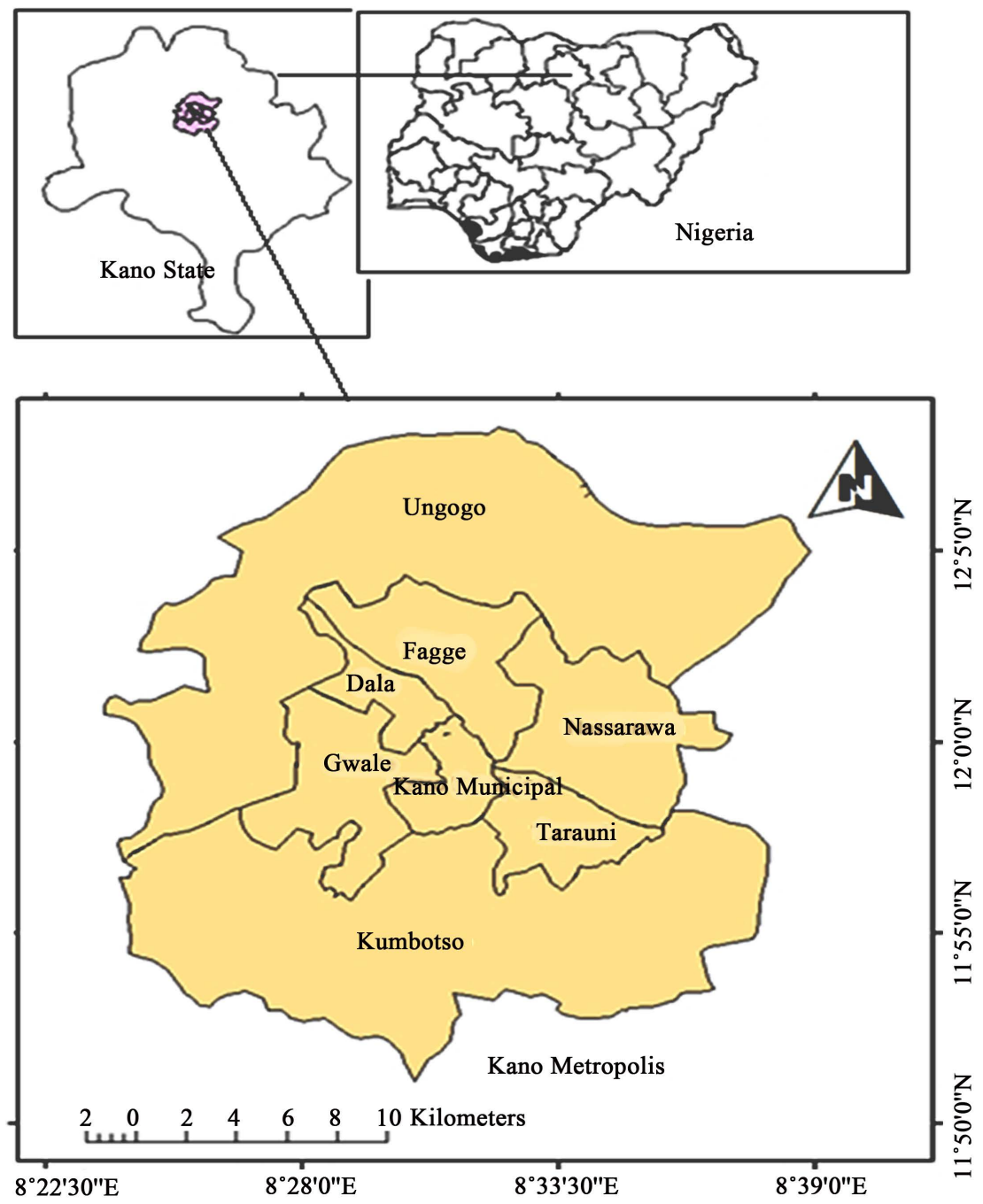

Figure 2. Metropolitan Kano. 
more than 10 million [23]. The demographic expansion of Kano was as a result of its good fertile landscape, commercial city, as well as its accessibility and hospitality. The metropolitan Kano has a population of more than 4 million and is the major trading hub of Northern Nigeria [23]. Similarly, the modern Kano metropolis is a conurbation of eight Local Government Areas (LGAs) around the main city, which metamorphose to form the present Kano metropolis. The LGAs are Dala, Fagge, Gwale, Kano Municipal, Nassarawa, Tarauni, Kumbotso and Ungogo. These eight LGAs formed the study area for this study.

\subsection{Data Sources}

Data for this study comprises both primary and secondary sources as follows: the primary data consists of about 300 waste disposal sites collected using Garmin handheld GPS from the eight LGAs within the metropolis. The secondary data consists a high-resolution QUICKBIRD imagery for 2014, topographical map of metropolitan Kano, at 1:5000 scale (obtained from Kano state ministry of Land) and solid waste disposal type and collection schedule from REMASAB.

\subsection{Methodology}

The schema of the methodology used for this study is presented in Figure 3. From Figure 3, the QUICKBIRD satellite image was handled in Erdas Imagine 11 software for Geometric and Radiometric Correction. ArcGIS 10.2.1 was used in the geometric correction of the topographical map as well as the creation of a simple database (using the location data of the waste disposal sites collected) and shapefiles for the entire project. The various data were then imported into ArcGIS, and using an overlay procedure, a spatial distribution map and other spatial analysis for the entire metropolis was achieved. The results are presented in the form of maps showing the locations of the entire disposal sites on the land use pattern of the metropolis.

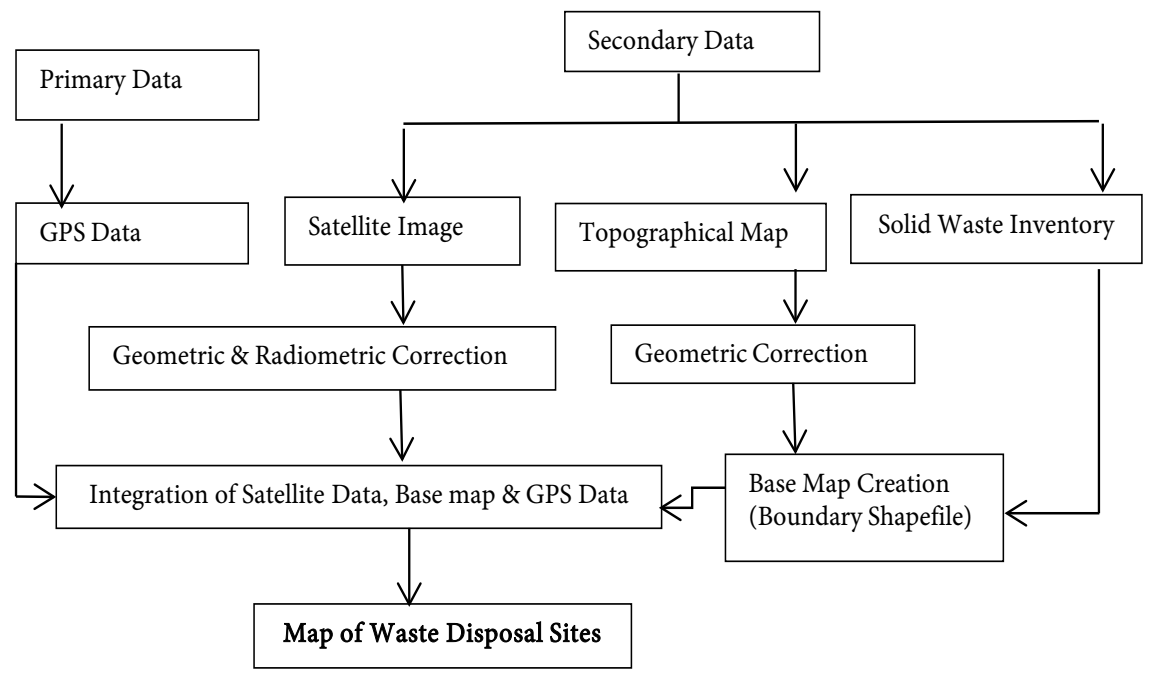

Figure 3. Flow chart of the methodology. 


\section{Result and Discussions}

\subsection{Distribution of Existing Solid Waste Disposal Sites in Kano Metropolis}

The various locations of the existing solid waste disposal sites are displayed in Figure 4. From Figure 4, most of the disposal sites are not properly located considering the environmental and social well-being of the people as suggested by Rahman et al. [10]. The figure further showed that more than 80 percent of the existing disposal sites are within the range of 30 to 50 meters distance from road networks and are therefore considered not properly sited. Nonetheless, the result of the status of waste disposal sites within the study area (Figure 5) suggests that less than 12 percent of the disposal sites are unauthorized.

This finding is contrary to the initial view of the researchers, whose preliminary investigation of the disposal sites prior to the actual study suggested that majority of the sites are illegal. Similarly, it was observed that the concentration of waste disposal sites decreases from the city centre as one move outwards. This was connected with the high concentration of economic activities and population in the city centre compared to the outskirts of the metropolis. This position was earlier put forward by Lancelet and Nija [24], whose study also confirmed a strong relationship between waste generation and concentration of population

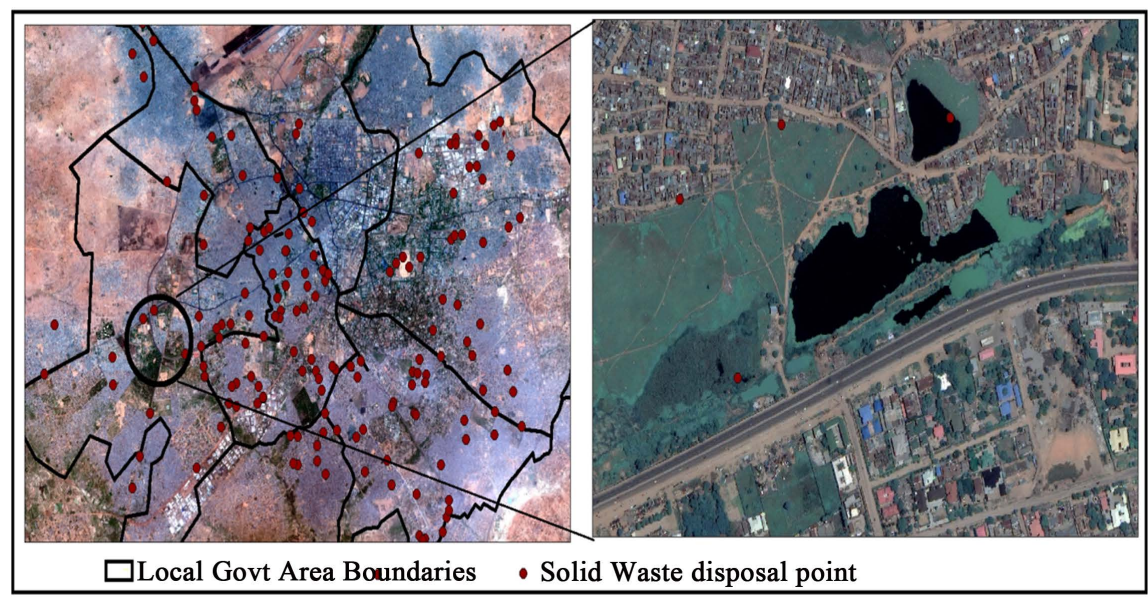

Figure 4. Distribution of solid waste disposal sites in the study area.

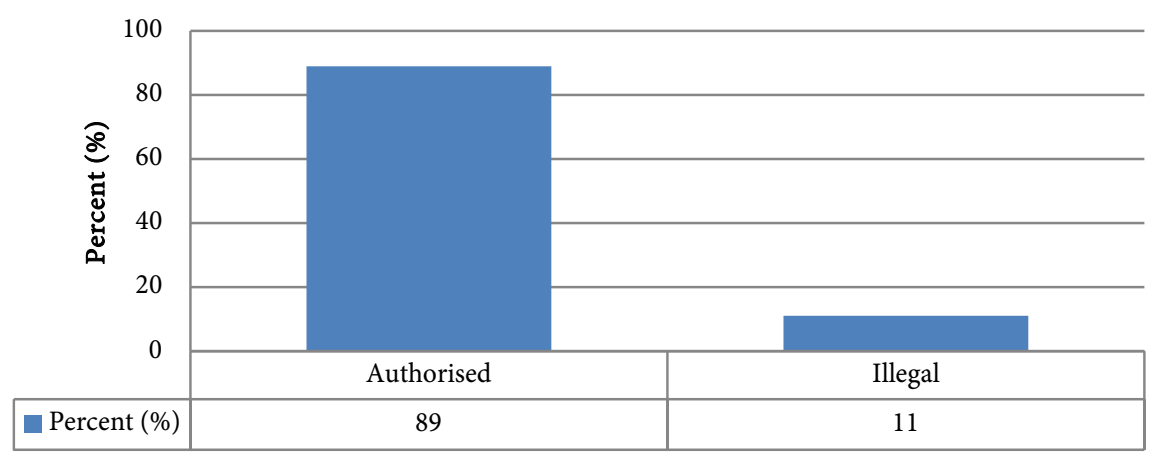

Figure 5. Status of solid waste disposal sites in Kano Metropolis. 
and economic activities in Thodupuzha municipality, Idukki district of Kerala state in India. Overall, unauthorized waste disposal sites constitute significant problems of many local authorities particularly in the suburbs or large urban areas of the developing countries. It is also our position that it is an environmental crime to illegally dispose of on public or private open plots or even discharged in the drains or water bodies, which may result in clogging of drains, pollution of water resources and increase in unsanitary conditions of the urban areas.

\subsection{Situation of Solid Waste Disposal Sites in Kano Metropolis}

Open dumpsites in developing urban cities are characterized by indiscriminate waste disposal. They are uncontrolled and therefore pose major health threats, which affect the landscape of urban cities [25] [26]. The findings of this study identified that about 93 percent of the 300 existing waste disposal sites investigated are open space dumping and only about $7 \%$ are collected in a container (see Figure 6 and Table 2 for an illustration). This conformed to the earlier assertion of UNEP [11], which highlighted that in most developing countries, open dumping is the norm in terms of waste disposal. However, it should be noted that the open dumpsite method is a primitive stage of solid waste management in many parts of the world. It is considered as one of the most poorly rendered services by municipal authorities in developing countries as the systems applied are unscientific, outdated and inefficient [26]. The waste is often dumped indiscriminately on open plots of land and particularly on streets (refer to Figure 6 and Table 2 for more details). This method is based on "throwaway culture" where wastes are disposed into the nearest open space, on land or surface water without environmental consideration [26]. Foday et al. [26] referred this to as "not in my backyard syndrome" where the waste is merely transferred from one location to another location where its nuisance value is perceived to be less.

Table 2. Status of some selected waste disposal sites in Kano Metropolitan.

\begin{tabular}{|c|c|c|c|c|c|c|}
\hline Location & Ward & LGA & Site Type & Status & $\begin{array}{l}\text { Area } \\
\left(\mathrm{m}^{2}\right)\end{array}$ & Tons \\
\hline Rijiyar Zaki & Rijiyar Zaki & Ungogo & Open Space & Authorised & 221 & 111 \\
\hline Kofar Mazugal & Gwammaja & Dala & Open Space & Authorised & 2000 & 16,000 \\
\hline Unguwa Uku Tasha & Unguwa Uku & Kumbotso & Open Space & Authorised & 3500 & 14,000 \\
\hline $\begin{array}{c}\text { Unguwa Uku } \\
\text { Behind Sec. Tarauni }\end{array}$ & Unguwa Uku & Tarauni & Open Space & Authorised & 4000 & 10,800 \\
\hline Bakin Bulo Yammadawa & Dorayi & Gwale & Open Space & Authorised & 7452 & 22,356 \\
\hline Hajj Camp (Kwakwachi) & Kwachiri & Fagge & Open Space & Authorised & 9000 & 27,000 \\
\hline Hauren Joka & Zango & KMC & Open Space & Un-authorised & 9000 & 90,000 \\
\hline Dakata Yan Gwangwan & Dakata & Nassarawa & Open Space & Authorised & 15,000 & 60,000 \\
\hline Gwale Cemetary & Sani Mainage & Gwale & Open Space & Un-authorised & 120,000 & 24,000 \\
\hline
\end{tabular}



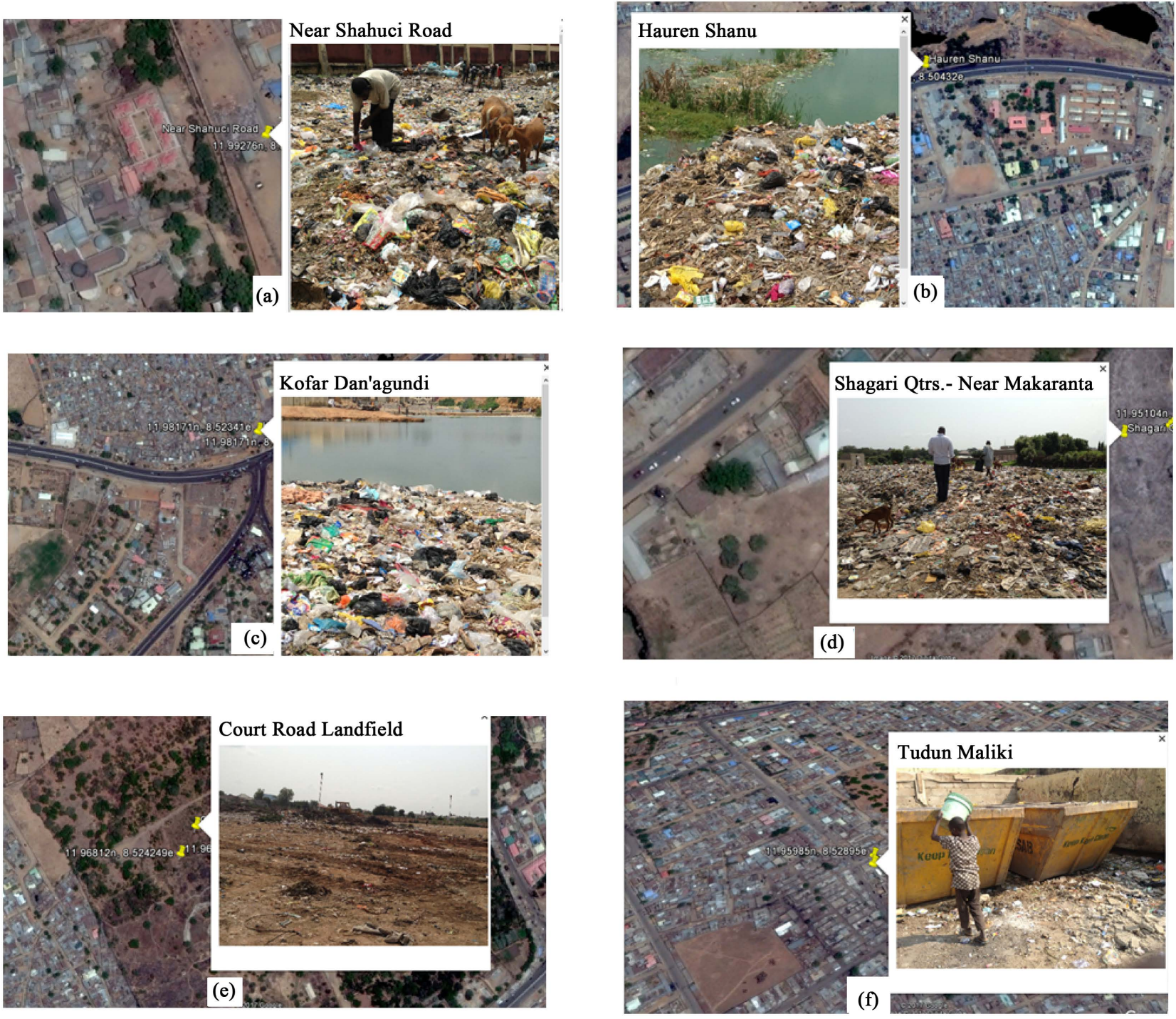

Figure 6. Open space dumping and container ((a)-(e) are open space dumping, while (f) is a container dumping site).

As highlighted in Table 2, there are various sizes of waste disposal sites within metropolitan Kano. The smaller areas range approximately between $9 \mathrm{~m}^{2}$ (mainly containers) and $500 \mathrm{~m}^{2}$ (mainly open space) (refer to Figure 6), while the larger ones range between $2000 \mathrm{~m}^{2}$ and $120,000 \mathrm{~m}^{2}$ (refer to Table 2 for more details). As pointed earlier, these solid waste disposal sites are found both within and outskirts of the Kano municipal. Certainly, with the current global population increase and the rising demand for food and other essentials, there has been a rise in the amount of waste being generated daily by households. These wastes are thrown into municipal waste disposal sites and due to poor and ineffective management, the dump sites turn to sources of environmental and health hazards to people living within the vicinity of such sites. One of the main aspects of concern is the pollution caused to the earth, be it land, air and water [26]. It is worth noting that the situation in Kano municipal is not different from most cities in the developing countries. For example, most cities in the developing 
countries face serious environmental degradation and health risks due to their inadequately developed municipal solid waste management system. In Nigeria, despite the numerous policies and regulations on solid waste, the country remains one of the largest producers of solid waste in Africa and solid waste management is assuming alarming proportions [13].

\section{Policy Implications, Conclusion and Recommendation}

\subsection{Policy Implications}

Solid waste disposal and management services are public services, in which the local authorities or respective municipal agencies should be responsible for its delivery. Even though private and individuals are involved in this task, it is imperative that municipal authorities should remain in charge of this task in order to achieve an overall metropolitan-wide consistency in solid waste management success. Similarly, private enterprise should be encouraged to participate more under appropriate conditions, to provide similar services provided by the public authorities. It is also important that the authorities should involve all stakeholders (private waste collectors, citizens, industries, academicians and various governmental and non-governmental environmental organizations) whenever it is planning for its solid waste management schemes.

\subsection{Conclusions}

The study used remote sensing satellite data and GIS in understanding the spatial distribution of existing waste disposal sites in Kano metropolis. The results of the study have shown that most of the waste disposal sites are not properly located because much consideration is not given to the environment and social implications of the current trend. It has also been noted that the distribution of solid waste disposal sites is related to the number of economic activities present in a particular area. That is why the disposal points are numerous at the centre of the metropolis compared to other places.

It should also be noted that the Kano state government has an agency (REMASAB) that supervises the activities of waste generation and collection; and a policy that encourages an end of month sanitation exercise that is aimed at cleaning the city. This paper suggests that the activities of such agency should be reviewed periodically in order to address the issue of illegal dumping of waste in areas that do not conform to the standards. Similarly, measures should be put in place to step up more stringent policies of waste dumping violation. The present policing of the performance of the policy programmes are inadequate because there is no recourse for periodic checks of the aftermath in order to assess the success or failure of the programmes. The lack of these periodic checks has resulted in the failure of most programmes in the country.

\subsection{Recommendations}

This paper suggests a further detailed research on the suitability assessment of 
the existing solid waste disposal sites, refuse collection, disposal and management in order to address the problem systematically. This is crucial because many diseases are a waste and refuse related, which can easily be spread out from the disposal or dumping sites.

\section{Acknowledgements}

This research was funded by the Nigerian Tertiary Education Trust Fund (TETFund). The authors also wish to acknowledge REMASAB staff for their cooperation during field investigation.

\section{References}

[1] Bringi, S.D. (2007) Application of 3D Principles to Solid Waste Management on the Asian. Unpublished M.Sc. Thesis, Institute of Technology (Ait) Campus, Indonesia.

[2] Hosetti, B.B. and Kumar, A. (1998) Environmental Impact Assessment \& Management. Daya Publishing Company, New Delhi.

[3] Sha' Ato, R., Aboho, S.Y., Oketunde, F.O., Eneji, I.S., Unazi, G. and Agwa, S. (2007) Survey of Solid Waste Generation and Composition in a Rapidly Growing Urban Area in Central Nigeria. Waste Management, 27, 352-358. https://doi.org/10.1016/j.wasman.2006.02.008

[4] Babatunde, B.B., Vincent-Akpu, I.F., Woke, G.N., Atarhinyo, E., Aharanwa, U.C., Green, A.F. and Isaac, J. (2013) Comparative Analysis of Municipal Solid Waste (MSW) Composition in Three Local Government Areas in Rivers State, Nigeria. African Journal of Environmental Science Technology, 7, 874-881.

[5] Tirusew, A.E. and Amare, S.M. (2013) Solid Waste Dumping Site Suitability Analysis Using Weighted Geographic Information System (GIS) and Remote Sensing for Bahir Dar Town, North Western Ethiopia. African Journal of Science and Technology, 7, 976-989.

[6] Singh, G.K., Gupta, K. and Chaudhary, S. (2014) Solid Waste Management: Its Sources, Collection, Transportation and Recycling. International Journal of Environmental Science and Development, 5, 347-351. https://doi.org/10.7763/IJESD.2014.V5.507

[7] Abul, S. (2010) Environmental and Health Impact of Solid Waste Disposal at Mangwaneni Dumpsite in Manzini: Swaziland. Journal of Sustainable Development Africa, 12, 1520-5509.

[8] Visvanathan, C. and Glawe, U. (2006) Domestic Solid Waste Management in South Asian Countries. A Comparative Analysis. $3 R$ South Asia Expert Workshop, Kathmandu, 30 August-1 September 2006.

[9] Hammer, G. (2003) Solid Waste Treatment and Disposal: Effect on Public Health and Environmental Safety. Biotechnology Advances, 22, 71-79.

[10] Rahman, M.D., Mujibor, K.R.S. and Ahasanul Hoque, M.D. (2008) Suitable Sites for Urban Solid Waste Disposal using GIS Approach in Khulna City, Bangladesh. Proceedings of the Pakistan Academy of Sciences, 45, 11-22.

[11] United Nations Environment Programme (UNEP) (n.d.) Solid Waste Management. https://www.unep.org/resourceefficiency/what-we-do/policy-strategy/resource-effic ient-cities/focus-areas-cities/solid-waste-management

[12] Hansen, C. (2015) Solid Waste Management in Nigeria. BioEnergy Consult, Powering Clean Energy Future. https://www.bioenergyconsult.com/2015/06/ 
[13] Bakare, W. (2016) Solid Waste Management in Nigeria. BioEnergy Consult, Powering Clean Energy Future. https://www.bioenergyconsult.com/tag/nigeria/

[14] Ossai, R.M. (2006) Moving Solid Waste Management into the 21st Century in Nigeria. Proceedings of the 6 th National Council on Environment Meeting, Kastina State Secretariat, Kastina.

[15] Agboje, I.A., Adeoti, A. and Irhivben, B.O. (2014) Performance Assessment of Solid Waste Management following Private Partnership Operations in Lagos State, Nigeria. Journal of Waste Management, 2014, 1-8.

[16] Nabegu, B.A. (2010) An Analysis of Municipal Solid Waste in Kano Metropolis, Nigeria. Journal of Human Ecology, 31, 111-119.

[17] Kawai, K. and Tasaki, T. (2016) Revisiting Estimates of Municipal Solid Waste Generation per Capita and Their Reliability. Journal of Material Cycles and Waste Management, 18, 1-13. https://doi.org/10.1007/s10163-015-0355-1

[18] Malumfashi, S.L., Muktar, M. and Adamu, Y.M. (2011) Constraints to Waste Management in Kano Metropolis, Northern Nigeria.

http://mustaphamuktar.blogspot.com/2011/01/constraints-to-waste-management-i $\underline{\text { n-Kano.html }}$

[19] Hussain, A., Begum, S., Hussain, S.W., Khan, Z. and Ali, A. (2016) Analysis of Management and Environmental Effects of Municipal Solid Waste Due to Inefficient Practices through People's Perception in Gilgit City, Gilgit Baltistan, Pakistan. International Journal of Scientific Research in Environmental Sciences, 4, 12-16. https://doi.org/10.12983/ijsres-2016-p00012-0016

[20] Marmara University Environmental Biotechnology Group (MEBiG) (2012) Marmara University Environmental Biotechnology Group “MEBiG”. Chapter 8 Collection of Solid Waste.

[21] Gilgit-Baltistan Environmental protection Agency (GB-EPA) (2013) Quantities and Characteristics of Solid Waste in Seven Urban Centers of Gilgit-Baltistan (GB), Gilgit-Baltistan Environmental Protection Agency, Pakistan.

[22] Mustapha, A. and Ahmad, H.I. (2017) Hydrochemistry Assessment of River Water Quality Variations in a Highly Heterogeneous Land Use Area along River Kano. Northwest Journal of Social and Management Sciences, 1, 54-71.

[23] National Population Commission of Nigeria (NPC) (2009) 2006 Facts and Figures. http://www.Population.gov.ng/factsandfigures2006

[24] Lancelet, T.S. and Nije, K.C. (2013) Spatial Variations and Composition of Solid Waste Generation in Thodupuzha Municipality, Idukki District, Kerala State. Scholar World IMRJCR, I (III).

[25] Sood, D. (2004) Solid Waste Management Study for Freetown (Component Design for World Bank, Draft Report Project No. P078389). Great Falls, Virginia.

[26] Foday, P.S., Xiangbin, Y. and Quangyen, T. (2013) Environmental and Health Impact of Solid Waste Disposal in Developing Cities: A Case Study of Granville Brook Dumpsite, Freetown, Sierra Leone. Journal of Environmental Protection, 4, 665-670. https://doi.org/10.4236/jep.2013.47076 